\title{
The effect of psychopathology on quality of life and disability in patients with fibromyalgia
}

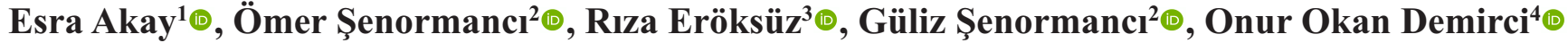 \\ ${ }^{1}$ Department of Psychiatry, Anamur State Hospital, Mersin, Turkey \\ ${ }^{2}$ Department of Psychiatry, University of Health Sciences, Bursa Yüksek Ihtisas Training and Research Hospital, Bursa, Turkey \\ ${ }^{3}$ Department Medical Ecology and Hydroclimatology, University of Health Sciences, Bursa Yüksek Ihtisas Training and Research \\ Hospital, Bursa, Turkey \\ ${ }^{4}$ Department of Psychology, Istanbul Gelisim University, Istanbul, Turkey
}

\section{ABSTRACT}

Objectives: The aim of the study was to investigate the relationship between pain, depression, anxiety, somatic amplification and alexithymia in patients with fibromyalgia syndrome (FMS), and on quality of life and disability. As a secondary goal, the predictors of disability were evaluated.

Methods: Participants were 112 female patients aged 18 and over, applied to the outpatient clinic of University of Health Sciences Bursa Yüksek İhtisas Training and Research Hospital Medical Ecology and Hydroclimatology department and diagnosed with FMS according to ACR 2016 Revised Fibromyalgia Diagnosis Criteria. The Sociodemographic Data Form, Visual Analog Scale (VAS), Beck Depression Inventory (BDI), Beck Anxiety Inventory (BAI), Toronto Alexithymia Scale (TAS-20), Somatosensory Amplification Scale (SSAS), Fibromyalgia Impact Questionnaire (FIQ) and Health Survey Questionnaire Short Form (SF36) were applied to each participant. All data were analyzed with correlation and linear regression.

Results: Increased pain intensity, depression, anxiety, somatic amplification, "difficulty identifying feeling" and "difficulty describing feelings" dimensions of alexithymia were found related to lower quality of life and increased disability. Depression, somatic amplification, and pain severity were defined as the predictors of disability in FMS.

Conclusions: Psychiatric examination of FMS patients especially in terms of depression, anxiety, alexithymia and somatic amplification as well as their physical complaints can be beneficial to minimize disability and increase the quality of life. To our best knowledge, this is the first study to show somatic amplification as a predictor of disability in FMS patients. Further studies will be helpful to understand this relationship.

Keywords: Alexithymia, anxiety, depression, fibromyalgia syndrome, quality of life, somatization

F ibromyalgia syndrome (FMS) is a chronic pain condition characterized by widespread body pain and excessive tenderness at specific body sites, and causes adverse effects on quality of life. FMS causes reduced functional capacity and difficulties in the fulfillment of daily life activities. Severe pain, the main symptom of the disease, causes reluctance and disability and negatively affects the functionality of the person $[1,2]$.

The etiology of FMS is not yet well-known. A significant part of the studies conducted to explain the etiology is on the relationship between psychiatric dis- 
orders and FMS [3]. Depression is the most comorbid psychiatric disorder with FMS. It has been shown that depressive symptoms increase as the pain severity and duration of pain increases $[4,5]$. One of the psychiatric symptoms most frequently seen in patients diagnosed with FMS is anxiety. It has been suggested that FMS patients with high anxiety symptoms show decreased physical activity and sedentary behaviors [6].

Alexithymia is defined as a disability to recognize one's own and other people's emotions. Taylor et al. [7]) reported that alexithymic personality traits were widely observed in FMS. Although depressive or anxiety symptoms of FMS patients are evident, they often seek help due to their widespread pain. This is thought to be due to the patients' inability to understand and express their emotions [7, 8]. Lumley et al. [9] suggested that alexithymic individuals may tend to misinterpret their emotional state as a sign of physical illness.

Alexithymia has also been associated with somatization as well as depression and anxiety [10]. Somatization concept defined as the person, experiencing and expressing physical/somatic symptoms that do not have a pathophysiological explanation, has a tendency to misinterpret them as a sign of illness and seek medical remedies [11]. It is well-known that somatic amplification is higher in various chronic pain syndromes such as headache, migraine, osteoarthritis, low back pain, neck pain, including FMS compared to healthy controls [12].

As a result, pain, depression, anxiety, alexithymia and somatic amplification may be related to each other and affect quality of life and disability in FMS patients. To the best of our knowledge, there is no study that evaluated these variables together in FMS patients. Thus, in this study, the aim was to investigate the relationship of pain, depression, anxiety, somatic amplification and alexithymia with each other, quality of life and disability in patients with fibromyalgia syndrome (FMS). In addition, secondary aim was to evaluate the predictors of disability.

\section{METHODS}

\section{Participants}

The study included 112 female patients who applied to the University of Health Sciences Bursa Yük- sek İhtisas Training and Research Hospital Medical Ecology and Hydroclimatology Clinic between September 2018 and April 2019 with widespread pain and diagnosed with FMS according to the American College of Rheumatology 2016 Revision Fibromyalgia Diagnostic Criteria [13]. Other inclusion criteria were: (1) 18-over age, (2) being literate, (3) volunteering to study. Exclusion criteria were: (1) mental disability/retardation, (2) neuro-cognitive disorders, (3) other organic mental disorders. All patients signed informed consent before participation. The tests were given in a single session with a randomized order. Prior to the research, ethics committee approval was obtained from University of Health Sciences Bursa Yüksek İhtisas Training and Research Hospital Clinical Research Ethics Committee on 25.07.2018 numbered 2011KAEK-25 2018/07-02.

\section{Instruments}

\section{Demographic Data Form}

The researchers developed a form to obtain sociodemographic data from the participants based on the objectives of the study.

\section{Visual Analog Scale (VAS)}

The scale developed by Price et al. (1983) measures the severity of the pain that the patient experienced [14]. The test consists of a $100 \mathrm{~mm}$ long straight line with the endpoints defining extreme limits: no pain to extreme pain. The patient required to mark the severity of his/her pain level between the two endpoints.

\section{Beck Depression Inventory (BDI)}

BDI is a 21 -item self-report inventory that measures the risk for depression and depressive symptoms [15]. The standardized Turkish form was used as a valid and reliable measurement [16]. Participants were asked to rate how they had been feeling for the last week. Higher total scores indicate more severe depressive symptoms.

\section{Beck Anxiety Inventory (BAI)}

BAI is again a 21-item, self-report inventory that is used for measuring the severity of anxiety levels. It questions the symptoms that the patient has experienced the last week. Higher total scores indicate more severe anxiety symptoms. The standardized Turkish 
form was used $[17,18]$.

\section{Toronto Alexithymia Scale (TAS-20)}

TAS is a 20-item, self-report scale as one of the most commonly used measures of alexithymia. Participants were required to rate using a 5-point likert scale from $1=$ strongly disagree to $5=$ strongly agree TAS has three subscales: (1) Difficulty Describing Feelings, (2) Difficulty Identifying Feelings, and (3) Externally Orienting Thinking. The standardized Turkish form was used to assess alexithymia levels of the patients $[19,20]$.

\section{Somatosensory Amplification Scale (SSAS)}

SASS is a simple and quick (requires less than 10 minutes) instrument designed to assess somatic and visseral sensations. It allows clinicians to evaluate somatosensory amplification in various diseases with fewer questions. SASS asks participant how much s/he experiences various uncomfortable somatic and visseral sensations most of which are not symptoms of a serious disease pathology. The valid and reliable Turkish form was for the assessment [21, 22].

\section{Health Survey Questionnaire Short Form (SF-36)}

It is a 36-item, self-report survey that questions the quality of life (QOL) especially in patients with physical illness. SF-36 consists of eight subscores: physical functioning, physical role functioning, bodily pain, general health perceptions, vitality, social role functioning, emotional role functioning, and mental health [23]. Scores for each domain are calculated by a scoring key and a total scoree indicating the level of QOL. The total scores range between 0-100 and lower scores represent the more severe disability. We used the valid and reliable Turkish form [24].

\section{Fibromyalgia Impact Questionnaire (FIQ)}

It is a 10 -item, self-report instrument to measure FM patient status, progress and outcomes [25]. It only takes five minutes to complete and requires the participant to mark their experience. It is used to measure self-feeling, pain, fatigue, inability to work, difficulty at work, snails, morning fatigue, anxiety and depression. The first item includes 11 4-point Likert scale questions about physical functioning. Items 2-3 ask the patient the number of days they felt well and unable to work due to FM symptoms. Items 4-10 meas- ure work difficulty, morning triedness, stiffness, anxiety, depression, pain and fatigue. The scores of each domain range from 0 (no impairment) to 10 (maximum impairment) and total score is maximum 100. Lower scores mean less effect of the disease. The standardized Turkish form was applied [26].

\section{Statistical Analysis}

All collected data were analyzed by SPSS 18.0 Windows package program. The normal distributions of continuous variables were examined with SaphiroWilk test. Pearson $\mathrm{r}$ correlation was used for normally distributed parameters whereas Spearman correlation was preferred for non-normally distributed parameters to analyze inter-scale relationships. Numeric variables were presented with values corresponding to mean \pm

\section{Table 1. Demographic and clinical characteristics of study sample $(n=112)$

$\mathrm{n}(\%)$
Mean \pm SD
Median (Min-Max)/

\begin{tabular}{|lc|}
\hline Age (years) & $45.0 \pm 10.1$ \\
\hline Length of education (years) & $5(5-20)$ \\
\hline Marital status & \\
\hline \multicolumn{1}{|c|}{ Single } & $21(18.8)$ \\
\hline Married & $91(81.2)$ \\
\hline Working status & \\
\hline Working & $31(27.7)$ \\
\hline No job & $81(72.3)$ \\
\hline Socioeconomic status & $24(21.4)$ \\
\hline Low & $88(78.6)$ \\
\hline Middle/high & $27.0 \pm 5.0$ \\
\hline BMI & $1.60(1.45-1.78)$ \\
\hline Height $(m)$ & $68(50-126)$ \\
\hline Weight $(\mathrm{kg})$ &
\end{tabular}

Psychiatric treatment history

$\begin{array}{ll}\text { Yes } & 70(62.5) \\ \text { No } & 42(37.5)\end{array}$

Comorbid medical conditions

$\begin{array}{ll}\text { Present } & 48(42.9) \\ \text { None } & 64(57.1)\end{array}$

BMI $=$ Body Mass Index 
standart deviation (mean $\pm \mathrm{SD}$ ) or median (Min-Max), while categorical variables were presented with the number of observations and percentage $(n-\%)$ notations. The alpha levels were $<0.05$ and $<0.01$ depending on the analysis. To test hypothesis, linear regression analysis was used.

\section{RESULTS}

\section{Demographical and Clinical Data}

Our study included 112 female FMS patients (mean age $=45.00 \pm 10.10$ years). Demographic and clinical characteristics of participants are given in Table 1 and scale scores are in Table 2.

The VAS scores had significant positive correlations with BDI $(\mathrm{r}=0.42, p<0.01)$, BAI $(\mathrm{r}=0.42, p<$ $0.01)$, TAS-20 difficulty identifying feelings subscale $(\mathrm{r}=0.29, p<0.01)$, TAS-20 difficulty describing feelings subscale $(\mathrm{r}=0.23, p<0.05)$, TAS-20 total scores $(\mathrm{r}=0.39, p<0.01)$, FIQ $(\mathrm{r}=0.62, p<0.01)$ and SASS $(r=0.24, p<0.01)$.

The FIQ scores had also showed positive correlations with $\mathrm{BDI}(\mathrm{r}=0.58, p<0.01)$, BAI $(\mathrm{r}=0.59, p<$ $0.01)$, TAS-20 difficulty identifying feelings subscale $(\mathrm{r}=0.49, p<0.01)$, TAS-20 difficulty describing feelings subscale $(\mathrm{r}=0.27, p<0.01)$, TAS-20 total score $(\mathrm{r}=0.40, p<0.01)$, and SSAS $(\mathrm{r}=0.42, p<0.01)$.

The SASS scores had significant positive correlations with BDI $(\mathrm{r}=0.40, p<0.01)$, BAI $(\mathrm{r}=0.60, p<$ $0.01)$, TAS-20 difficulty identifying feelings subscale $(\mathrm{r}=0.46, p<0.01)$, TAS-20 difficulty of describing feelings subscale $(\mathrm{r}=0.32, p<0.01)$ and TAS-20 total $(\mathrm{r}=0.40, p<0.01)$ besides VAS and FIQ.

The comparisons between SF-36 and VAS, FIQ, BDI, BAI, TAS-20, SSAS was reported in Table 3.

\section{Predictors of FIQ}

Linear regression analysis was performed to test the effects of demographic, clinical characteristics,

Table 2. Scores obtained by participants from the scales $(\mathbf{n}=112)$

\begin{tabular}{lc}
\hline & $\begin{array}{c}\text { Mean } \pm \text { SD } \\
\text { Median (Min-Max)/ }\end{array}$ \\
\hline BDI & $18.9 \pm 10.6$ \\
BAI & $23.5(0-59)$ \\
VAS & $58.9 \pm 21.5$ \\
FIQ & $54.4 \pm 19.5$ \\
SSAS & $30.2(10-48)$ \\
TAS-20 Difficulty identifying feeling & $18(7-35)$ \\
TAS-20 Difficulty describing feelings & $14(5-25)$ \\
TAS-20 Externally-oriented thinking & $21(8-30)$ \\
TAS-20 Total & $53.6 \pm 12.4$ \\
SF-36 Physical functioning & $60(0-100)$ \\
SF-36 Role function (physical) & $25(0-100)$ \\
SF-36 Pain & $50(0-90)$ \\
SF-36 General health & $55(20-85)$ \\
SF-36 Vitality & $50(15-80)$ \\
SF-36 Social functioning & $50(0-87.5)$ \\
SF-36 Role function (emotional) & $33.3(0-100)$ \\
SF-36 Mental health & $52(24-72)$ \\
\hline BDI - Beck Depressin
\end{tabular}

BDI = Beck Depression Inventory, BAI = Beck Anxiety Inventory, VAS = Visual Analog Scale, FIQ = Fibromyalgia Impact Questionnaire, SSAS $=$ Somatosensory Amplification Scale, TAS-20 $=$ Toronto Alexithymia Scale, SF-36 = Health Survey Questionnaire Short Form 
Table 3. Relationship between SF-36 and VAS, FIQ, BDI, BAI, TAS-20, SSAS scores in the study sample $(\mathrm{n}=$ 112)

\begin{tabular}{|c|c|c|c|c|c|c|c|c|}
\hline & \multicolumn{8}{|c|}{ SF-36 } \\
\hline & $\begin{array}{c}\text { Physical } \\
\text { functioning }\end{array}$ & $\begin{array}{c}\text { Role function } \\
\text { (physical) }\end{array}$ & Pain & $\begin{array}{c}\text { General } \\
\text { health }\end{array}$ & Vitality & $\begin{array}{c}\text { Social } \\
\text { functioning }\end{array}$ & $\begin{array}{c}\text { Role function } \\
\text { (emotional) }\end{array}$ & $\begin{array}{c}\text { Mental } \\
\text { health }\end{array}$ \\
\hline & $\mathbf{r}$ & $\mathbf{r}$ & $\mathbf{r}$ & $\mathbf{r}$ & $\mathbf{r}$ & $\mathbf{r}$ & $\mathbf{r}$ & $\mathbf{r}$ \\
\hline VAS & $-.44 * *$ & $-.37 * *$ & $.57 * *$ & $.19 *$ & -.13 & .03 & $-.39 * *$ & $-.37 * *$ \\
\hline FIQ & $-.54 *$ & $-.54 *$ & $.65^{*}$ & .16 & -.04 & .10 & $-.54 *$ & $-.31 *$ \\
\hline BDI & $-.42 * *$ & $-.27 * *$ & $.36^{* *}$ & .10 & .08 & $.22 *$ & $-.35 * *$ & $-.40 * *$ \\
\hline BAI & $-.54 * *$ & $-.35 * *$ & $.44 * *$ & .14 & -.06 & $.22 *$ & $-.46^{* *}$ & $-.38 * *$ \\
\hline SSAS & $-.42 * *$ & $-.26 * *$ & $.34 * *$ & -.05 & -.05 & .11 & $-.37 * *$ & -.15 \\
\hline $\begin{array}{l}\text { TAS-20 difficulty } \\
\text { identifying } \\
\text { feeling }\end{array}$ & $-.34 * *$ & -.18 & $.32 * *$ & .00 & -.00 & .14 & $-.37 * *$ & $-.31 * *$ \\
\hline $\begin{array}{l}\text { TAS-20 difficulty } \\
\text { describing } \\
\text { feelings }\end{array}$ & $-.23 *$ & -.11 & $.20^{*}$ & .01 & .12 & $.25^{* *}$ & $-.25 * *$ & $-.27 * *$ \\
\hline $\begin{array}{l}\text { TAS- } 20 \\
\text { externally- } \\
\text { oriented thinking }\end{array}$ & .05 & .05 & -.04 & .07 & .00 & .03 & .01 & .06 \\
\hline TAS-20 Total & $-.29 * *$ & -.15 & $25 * *$ & .04 & .02 & $.18^{*}$ & $-.32 * *$ & $-.28 * *$ \\
\hline
\end{tabular}

SF-36 = Health Survey Questionnaire Short Form, VAS = Visual Analog Scale, FIQ = Fibromyalgia Impact Questionnaire, BDI = Beck Depression Inventory, BAI = Beck Anxiety Inventory, SSAS = Somatosensory Amplification Scale, TAS-20 = Toronto Alexithymia Scale

VAS, BDI, BAI, SSAS, TAS-20 scales on FIQ scores. The predictors of the model were significant FMS duration $(p<0.05)$, VAS, BDI, BAI, SSAS, TAS-20 difficulty identifying feelings. The analysis was performed via "backward stepwise" method. Respectively, following predictors were eliminated: FMS duration in step 2, BAI in step 3, TAS-20 difficult identifying feeling in step 4 . As a result, the regression model was statistically significant $(\mathrm{F}=46.771, p<$ $0.01)$. FIQ increased by 0.419 units $(\beta=0.419, p<$ 0.01 ) when VAS increased by one unit, FIQ increased by 0.419 units $(\beta=0.655, p<0.01)$ when BDI increased by one unit, and FIQ increased by 0.388 units $(\beta=0.655, p=0.020)$ when SSAS increased by one unit. VAS, BDI, SSAS can explain 0.553 variance of FIQ (Table 4).

\section{DISCUSSION}

In the present study, the binary relationships between pain, depression, anxiety, somatic amplification and alexithymia, and their relationships with quality of life and disability were examined in patients with FMS. It was found that depression, somatic amplification and pain severity were the predictors of disability.

The findings also showed that pain severity was

Table 4. Predictors of FIQ

\begin{tabular}{lcccc}
\hline $\begin{array}{l}\text { Dependent } \\
\text { variable }\end{array}$ & $\begin{array}{c}\text { Independent } \\
\text { variable }\end{array}$ & $\boldsymbol{\beta}$ & $\boldsymbol{p}$ value & Model $(\boldsymbol{p})$ \\
\hline FIQ & Constant & 5.645 & 0.287 & $<\mathbf{0 . 0 1}$ \\
& VAS & 0.419 & $<\mathbf{0 . 0 1}$ & \\
& BDI & 0.655 & $<\mathbf{0 . 0 1}$ & \\
\hline SSAS & 0.388 & $\mathbf{0 . 0 2 0}$ & \\
\hline
\end{tabular}

Linear regression, $p<0.01$, Adjusted $\mathrm{R}$ Square $=0.553$, FIQ=Fibromyalgia Impact Questionnaire, VAS $=$ Visual Analog Scale, BDI = Beck Depression Inventory, SSAS = Somatosensory Amplification Scale 
positively correlated with depression, anxiety, alexithymia and somatic amplification. Pain severity was also positively correlated with worsening quality of life and increased disability. Besides pain negatively affects quality of life, it also has negative effects on mood, sleep patterns, daily work and activities, mental state and vitality [27]. It has been reported that pain is the most important predictor of quality of life and disability in FMS patients [28].

Participants in our study had mild-moderate depressive symptoms and moderate-severe anxiety symptoms. The most common psychiatric disorders in FMS are depression and anxiety disorders. Comorbidity of depression, anxiety and FMS that have common pathophysiology and respond to similar treatments led to the view of a single underlying condition of depression, anxiety and FMS appears with different symptoms [29]. It has been suggested that somatoform diseases, including FMS, and depression comorbidity are associated with all functionality and quality of life indices, while reporting that anxiety has a relatively narrower effect [30]. It has been found that depression is an important predictor especially for SF-36 vitality and mental health subscales and FIQ, while anxiety is a predictor of SF-36 general health, social role functioning, mental health and emotional role difficulties [28].

We also found a positive correlation between pain severity and depression and anxiety. The presence of depression and/or anxiety in FMS patients is a factor to increase pain severity. A study compared the pain and symptom severity of FMS patients with and without depression and found that patients with depression had experienced more severe pain compared to nondepressed patients. In the same study, it was also evident that pain severity was higher in FMS patients with anxiety compared to patients without anxiety. The study reported that the existence of depression and anxiety in chronic pain conditions was associated with more severe pain, disability and lower quality of life [31]. The relationship between pain, depression and anxiety was explained by psychological mechanisms. Hypervigilance and catastrophe may mediate the relationship between these three states by increasing the physical and psychological symptoms of the patient. Thus, it has been stated that the one's perception of pain may increase in the context of depression and anxiety [32].
Findings on the relationship of somatic amplification in chronic pain conditions with QOL and disability are limited. It has been reported that increase in somatic symptom burden has negative effects on QOL in patients with chronic lumbar pain [33]. Moreover, It has been stated that somatic amplification has a significant effect on disability of patients with chronic lumbar pain whereas it has no effect on QOL and disability of patients with chronic neck pain [34, 35]. It was also shown that somatization is associated with intensity of pain, functional status and recovery perception in patients with chronic lumbar pain [36]. Additionally, somatization and pain disaster had negative effects on pain and QOL through alexithymia on patients with headache [37].

As far as we know, our study is the first to evaluate the effect of somatic amplification on QOL and disability in FMS. We found that somatic amplification has negative impact on QOL of FMS patients, especially in physical and emotional situations. The regression analysis showed that somatic amplification is also a predictor of disability in FMS. Negative effects of somatization on QOL and disability in FMS patients can be explained the fact that the impact of somatization on decreased physical activity of the individual, the duration of pain, depression and its relationship with alexithymia. Further studies are needed to explore the mechanism of how somatization affects the QOL and disability in patients with FMS. Further study is needed on the mechanisms through which somatization effects on quality of life and loss of ability in patients with FMS.

We also found that the two dimensions of alexithymia, "difficulty identifying feelings" and "difficulty describing feelings" have negative effects on the physical and psychological dimension of QOL and relate to disability. Alexithymia increases pain sensitivity and emotional pain experience. It has been suggested that alexithymia has adverse effects on psychosocial and physical dimension of QOL by mediating psychiatric symptoms [38]. Another study also argued that alexithymia negatively affects QOL through depression and other psychiatric disorders. Additionally, they suggested that people with alexithymic characteristics experience more difficulties in identifying and describing emotions and thus, perceive emotions as a somatic symptom, so alexithymia is a predisposing factor for somatization [39]. In our study, 
the negative effect of alexithymia on pain may have affected the QOL of FMS patients through psychiatric effects and somatic amplification.

\section{CONCLUSION}

We investigated the factors affecting QOL and disability in FMS. The findings showed that pain severity, symptoms of depression and anxiety and somatic amplification, "difficulty identifying feeling" and "difficulty describing feelings" dimensions of alexithymia have impacts on QOL and disability and pain severity, depression and somatic amplification are the predictors of disability of FMS patients. The present study is the first to show somatic amplification as a predictor of disability in FMS patients. Further studies may help to understand this relationship. Consequently, FMS patients should be examined for both physical and psychiatric symptoms in detail. If necessary, they may receive a psychiatric treatment as well. Evaluation of depression, anxiety, alexithymia and somatic amplification of FMS patients can be beneficial to minimize disability and increase QOL.

\section{Authors' Contribution}

Study Conception: ÖȘ, OOD; Study Design: ÖŞ, EA, GŞ; Supervision: ÖȘ, RE, GŞ; Funding: RE, EA; Materials: RE, EA; Data Collection and/or Processing: EA; Statistical Analysis and/or Data Interpretation: ÖŞ, EA, OOD; Literature Review: EA, OOD, RE; Manuscript Preparation: EA, ÖŞ and Critical Review: ÖŞ, OOD, RE, GŞ.

\section{Conflict of interest}

The authors disclosed no conflict of interest during the preparation or publication of this manuscript.

\section{Financing}

The authors disclosed that they did not receive any grant during conduction or writing of this study.

\section{REFERENCES}

1. Sivas FA, Başkan BM, Aktekin LA, Çınar NK, Yurdakul FG, Özoran K. [Assessment of depression, sleep disorders and quality of life in patients with fibromyalgia]. Turk J Phys Med Rehab
2009;55:8-12. [Article in Turkish]

2. Özcan DS, Aras M, Köseoğlu BF, Güven ŞŞ. [Quality of life and associated conditions in women with fibromyalgia syndrome]. Turk J Osteoporos 2013;19:42-7. [Article in Turkish] 3. González E, Elorza J, Failde I. Fibromyalgia and psychiatric comorbidity: their effect on the quality of life patients. Actas Esp Psiquiatr 2010;38:295-300.

4. Madenci E, Herken H, Yağız E, Keven S, Gürsoy S. [Depression levels and the ways of coping with pain in patients with chronic pain and fibromyalgia syndromes]. Turk J Phys Med Rehabil 2006;52:19-21. [Article in Turkish]

5. Martinez JE, Casagrande P, Ferreira PP, Rossatto BL. Correlation between demographic and clinical variables and fibromyalgia severity. Rev Bras Reumatol 2013;53:460-3.

6. McDowell CP, Cook DB, Herring MP. The effects of exercise training on anxiety in fibromyalgia patients: a meta-analysis. Med Sci Sports Exerc 2017;49:1868-76.

7. Taylor GJ, Parker JD, Bagby RM, Acklin MW. Alexithymia and somatic complaints in psychiatric out-patients. J Psychosom Res 1992;36:417-24.

8. Taylor GJ. Alexithymia: concept, measurement, and implications for treatment. Am J Psychiatry 1984;141:725-32.

9. Lumley MA, Stettner L, Wehmer F. How are alexithymia and physical illness linked? A review and critique of pathways. J Psychosom Res 1996;41:505-18.

10. Hosoi M, Molton IR, Jensen MP, Ehde DM, Amtmann S, O'Brien S, et al. Relationships among alexithymia and pain intensity, pain interference, and vitality in persons with neuromuscular disease: considering the effect of negative affectivity. Pain 2010;149:273-7.

11. Lipowski ZJ. Somatization: a borderland between medicine and psychiatry. CMAJ 1986;135:609-14.

12. Burke ALJ, Mathias JL, Denson LA. Psychological functioning of people living with chronic pain: a meta-analytic review. Br J Clin Psychol 2015;5:345-60.

13. Wolfe F, Clauw DJ, Fitzcharles MA, Goldenberg DL, Häuser W, Katz RL, et al. 2016 Revisions to the 2010/2011 fibromyalgia diagnostic criteria. Semin Arthritis Rheum 2016;46:319-29.

14. Price DD, McGrath PA, Rafii A, Buckingham B. The validation of visual analogue scales as ratio scale measures for chronic and experimental pain. Pain 1983;17:45-56.

15. Beck AT, Ward CH, Mendelson M, Mock J, Erbaugh J. An inventory for measuring depression. Arch Gen Psychiatry 1961;4:561-71.

16. Hisli N. [Reability and validity of Beck Depression Inventory among university students]. J Turk Psychol 1989;7:3-13. [Article in Turkish]

17. Beck AT, Epstein N, Brown G, Steer RA. An invention for measuring clinical anxiety: psychometric properties. J Consult Clin Psychol 1988;56:893-7.

18. Ulusoy M, Erkmen H, Şahin N. Turkish version of the Beck Anxiety Inventory: psychometric properties. J Cog Psychother 1998;12:163-72.

19. Bagby RM, Parker JDA, Taylor GJ. The twenty-item Toronto Alexithymia Scale-I Item selection and cross validation of the factor structure. J Psychosom Res 1994;38:23-32.

20. Güleç H, Köse S, Güleç MY, Çitak S, Evren C, Borckardt J, 
et al. Reliability and factorial validity of the Turkish version of the 20-Item Toronto alexithymia scale (TAS-20). Bull Clin Psychopharmacol 2009;19:214-20.

21. Barsky AJ, Wyshak G, Klerman GL. The somatosensory amplification scale and its relationship to hypochondriasis. J Psychiatr Res 1990;24:323-34.

22. Güleç H, Sayar K, Yazici M. [The reliability and validity of the Turkish form of the somatosensory amplification scale]. Düşünen Adam 2007;20:16-24. [Article in Turkish]

23. Ware J, Sherbourne C. The MOS 36-item shortform health survey (Sf-36): I. conceptual framework and item selection. Med Care 1992;30:473-83.

24. Koçyiğit H, Aydemir Ö, Fişek G, Memiş A. [Reliability and validity of the Turkish version of Short form-36]. İlaç ve Tedavi Dergisi 1999;12:102-6. [Article in Turkish]

25. Burckhardt CS, Clark SR, Bennett RM. The fibromyalgia impact questionnaire: development and validation. J Rheumatol 1991;18:728-33.

26. Sarmer S, Ergin S, Yavuzer G. The validity and reliability of the Turkish version of the Fibromyalgia Impact Questionnaire. Rheumatol Int 2000;20:9-12.

27. Turk DC, Robinson JP, Burwinkle T. Prevalence of fear of pain and activity in patients with fibromyalgia syndrome. J Pain 2004;5:483-90.

28. Campos RP, Vázquez Rodríguez MI. Health-related quality of life in women with fibromyalgia: clinical and psychological factors associated. Clin Rheumatol 2012;31:347-55.

29. Işı1k Ulusoy S. Evaluation of affective temperament and anxiety-depression levels in fibromyalgia patients: a pilot study. Braz J Psychiatry 2019;41:428-32.

30. Liao SC, Ma HM, Lin YL, Huang WL. Functioning and quality of life in patients with somatic symptom disorder: The association with comorbid depression. Compr Psychiatry
2019;90:88-94.

31. Singh G, Kaul S. Anxiety and depression are common in fibromyalgia patients and correlate with symptom severity score. Indian J Rheumatol 2018;13:168.

32. Fernandez E. Anxiety, depression, and anger in pain. Dallas: Advanced Psychological Resources, Inc; 2002.

33. Fujii T, Oka H, Katsuhira J, Tonosu J, Kasahara S, Tanaka S, et al. Association between somatic symptom burden and healthrelated quality of life in people with chronic low back pain. PLoS One 2018;13:e0193208.

34. Güçlü DG, Güçlü O, Ozaner A, Şenormancı Ö, Konkan R. The relationship between disability, quality of life and fearavoidance beliefs in patients with chronic low back pain. Turk Neurosurg 2012;22:724-31.

35. Güçlü DG, Senormancı Ö, Güçlü O, Çırak M, Konkan R, Erkıran M. [The effect of psychopathology on quality of life and disability of patients with chronic neck pain]. Turkiye Klinikleri J Med Sci 2013;33:702-10. [Article in Turkish]

36. Ailliet L, Rubinstein SM, Knol D, van Tulder MW, de Vet HC. Somatization is associated with worse outcome in a chiropractic patient population with neck pain and low back pain. Man Ther 2016;21:170-6.

37. Shim EJ, Park A, Park SP. The relationship between alexithymia and headache impact: the role of somatization and pain catastrophizing. Qual Life Res 2018;27:2283-94.

38. Tesio V, Di Tella M, Ghiggia A, Romeo A, Colonna F, Fusaro $\mathrm{E}$, et al. Alexithymia and depression affect quality of life in patients with chronic pain: A study on 205 patients with fibromyalgia. Front Psychol 2018;9:442.

39. Taycan O, Özdemir A, Erdoğan Taycan S. Alexithymia and somatization in depressed patients: the role of the type of somatic symptom attribution. Noro Psikiyatr Ars 2017;54:99-104. 